Interdisciplinary Studies of Complex Systems

No. 19 (2021) 35-47

(C) O.Stryzhak, S. Dovgyi, V. Demianenko, M. Popova, O. Gayevska

https://doi.org/10.31392/iscs.2021.19.035

UDC 001:37]:004.77

\title{
Cognitive DigitAl PLATFORMS \\ OF SCIENTIFIC EDUCATION
}

\author{
Oleksandr Stryzhak ${ }^{12}$, Stanislav Dovgyi ${ }^{1,3}$, Valentyna Demianenko ${ }^{1,4}$, \\ Maryna Popova ${ }^{1,5}$, Olena Gayevska ${ }^{6}$
}

\begin{abstract}
The digitalization of modern society, the emergence of the knowledge economy and the establishment of the principle of lifelong learning have led to the development of applied information and communication technologies in the educational process. One of the promising directions of the development of e-learning systems is the development of open educational systems using cognitive ICTs. The article discusses a knowledge-oriented approach to the formation of open educational systems based on the ontology and transdisciplinarity that provides the user with a holistic, systematic overview of a specific domain conceptualization of a specific knowledge area, represented by defining basic objects and connections between them. The authors describe cognitive software complex TEDAOS, which is intended for the construction of educational local and network (distributed) systems based on contextsemantic analysis and ontologies (from the local ontology-driven system of the educational process provision to the system of integrated multifactor analysis of educational information resources through the decision-making system and management of knowledge formation process) to ensure the interaction of all users of online information and educational environments. The Web-software complex "Knowledge Base Ontological Scenarios Editor" for formalizing the process of preparation, conduct and assessment of learning outcomes using an e-scenario is presented.
\end{abstract}

Keywords: open educational system, ontology, ontology-driven system, narrative discourse, transdisciplinarity

\section{Introduction}

Today, when the humanities are generally concerned about the global "spiritual crisis", the primary responsibility lies with the educational system, which is based on the modern requirements: preservation of human spiritual and cultural values and affirmation of new ones. Education must build and affirm the imperatives that structure reality and transform the world from "chaos"

\footnotetext{
${ }^{1}$ National Center "Junior Academy of Sciences of Ukraine", Kyiv, Ukraine

2 sae953@gmail.com, https://orcid.org/0000-0002-4954-3650

3 sodovgyi123@gmail.com, https://orcid.org/0000-0003-1078-0162

${ }^{4}$ valentyna.demianenko@gmail.com, https://orcid.org/0000-0002-8040-5432

${ }^{5}$ pm@man.gov.ua, https://orcid.org/0000-0002-0258-1713

6 Taras Shevchenko National University of Kyiv, olenasan@gmail.com, https://orcid.org/ 0000-0001-6850-8757
} 
to "space" and also deliver on a life-affirming world outlook. Its main determination is to give the educational process a humanistic sense, which means to transform a learner from an "object" into a "subject" of educational activity. As a result, a new society emerges, which is characterized by the intensification of cultural ties and exchanges, the growth of cultural diversity, shifting away from unification and standardization of human personality formation in the era of the industrial society [1]. In a knowledge-based society, the focus is made on shifting to the sphere of knowledge generation. Under these conditions, education becomes a special sphere and a priority component of social life, social and cultural phenomenon, unique system, ensuring the accumulation of knowledge, skills and human intellectual development. Learners in science education often have to deal with complex concepts or processes that are often considered difficult to grasp.

Digital technologies can help to promote knowledge acquisition and understanding in this context. However, such computer-based learning environments usually require learners to accept a high level of individual responsibility regarding their own learning process [2]. In order to withstand the chaos, developing behavioural strategies in such environments require new preventive educational strategies. Ensuring obtaining of the integral knowledge as a priority of new educational approaches ought to restore the harmony of relations of humans with nature, reduce social exclusion of a modern learner. The development of an educational system, on the one hand, and the need to learn continuously throughout one's life, on the other hand, establish the modern principles, goals, constraints, mechanisms and tools for the development of computer-oriented, open educational systems. The results of recent achievements in the theory of open educational systems and the regularities of their functioning serve as general methodological grounds for their pedagogical design. The main vector of research is aimed at formalizing the stages of construction, structuring and presentation of scientific information sources of domains in open educational systems and creating cognitive digital platforms for them.

The paper is structured as follows: Section 2 is dedicated to the analysis of the main data sources about education and knowledge generation strategies. Section 3 describes existed approaches to the implementation of ICTs in education. Section 4 provides features of the ontology approach to the implementation of scientific and educational systems. Section 5 describes cognitive technology TEDAOS for the development of educational and research local and network (distributed) systems based on ontologies. Section 6 presents Websoftware complex "Knowledge Base Ontological Scenarios Editor" for formalizing the process of preparation, conduct and assessment of learning outcomes using a cognitive, step-by-step, structured system of forming an ontological knowledge base - e-scenario, which is designed to organize the educational interaction of participants in the educational process. The results of the paper are summarized in the Conclusion. 


\section{State of art}

The paradigm of the modern information society is a network-orientated interaction between all its institutions and system components. The dynamic development of the Internet has facilitated progressive changes of the leading functional and technological characteristics of information and communication networks and gradual improvement of the user, information, communication, operational and procedural properties: from the closed local ones at the first or initial stage to the open ones - information delivery - at the second stage, information content (semantic) ones at the third stage, information service ones at the fourth stage and, eventually, information adaptive ones at the present, fifth stage. The World Wide Web has become the very environment in which the cognitive and communicative scenario of educational development unfolds. Its central link is the knowledge engineering technology, based on the use of IT-BigData, Semantic-WEB and Data Mining, which enables all learning processes in an educational environment [3-7]. Therefore, the success of this direction largely depends on the intellectual level and the overall effectiveness of interlinks between network information and educational systems. Using cognitive ICTs in the educational process can improve the learning effectiveness and promote the cognitive interest of learners for studies and research activities, create positive motivation for learning. Many commentators have suggested that the use of new information and communications technologies (ICTs) has significant potential in providing access to and improving the quality of teacher education [8].

Creating e-environments for the effective interaction of all participants in the educational process (learners, teachers, parents, methodological experts and managers) is possible subject to the use of electronic textbooks, repositories of digital educational resources, virtual laboratories, multimedia training tools, rating systems of educational achievements etc. [9]. In addition, these tools contribute to the development of critical thinking and reflection on the part of the student youth, since students become involved in modelling the studied object and can observe and evaluate the results of their actions [10]. Meanwhile, we stress the need to find new cognitive paradigms covering the classifications of knowledge, concepts, essence of scientific categories related to processes occurring in the learning environment, especially in the open, computer-oriented one.

\section{Use of Cognitive ICTs in the Educational Process}

While developing the information sources management systems, the problematic issue is not a software aspect but the finding, formulating, developing, structuring and presenting data and messages, which subsequently form the knowledge.

ICT system is an element of open educational systems, which provides an effective implementation of ICT processes, computer-aided collection and processing of data using an appropriate means of computer and information technologies. ICT tools and technologies in open educational systems form a flexible and adaptive integrated organization, technological, information and 
computing environment, which enables the most favourable (information comfortable) conditions for the effective implementation of its functions [11]. Meanwhile, the requirements for enhancing the productivity and reliability of ICTs with the constant growth of the volume of processed data are increasing. One of the tasks of activity in such environments is to provide conditions for the effective use of information resources by all members of the educational process - learners, teachers, experts, trainers and other professionals - to involve learners in research, prepare for the participation in contests, competitions and admission to higher educational institutions. For this purpose, the tools for the formalization of educational information sources of knowledge formation are created, taking into account the specifics of the educational processes at different types of educational institutions.

Creating open educational systems should include two important components, i.e. creating and maintaining a modern, powerful, adaptive hardware and software environment and filling it with pedagogically appropriate and methodically weighted subject content $[12,13]$. The application of ICT software components ensures the creation and use of educational and scientific databases of sources, being the framework for individual approach in education. By using ICT software and information tools in educational and research activities of learners, we take into account the fact that the volume and variety of data and messages for different profiles of knowledge is so big now that it is necessary to classify them in terms of belonging to subject fields or areas of interest of all educational research participants. It concerns not only the data stored in specialized databases or information repositories but also dynamic messages, which are generated by specific sources, as needed.

During the formation of a personalized educational system, each learner must accumulate not separate data but structured, formalized information sources - laws and principles, which allow the effective performance of assigned tasks. This largely becomes possible thanks to the emergence of new online computer-aided learning tools and open computer-based educational platforms providing learning support [14]. They ensure computer support of activity through the Internet, user and intranet services. User services are designed to provide flexible access to the scientific and educational information resources available to a wide (theoretically unlimited) circle of potential users. In turn, the functions of intranet services are aimed at ensuring the collection, accumulation, updating and storage of various information sources, the formation, structuring and reorganization of their composition, as well as the implementation of intranet communications and their protection against unauthorized access. Based on such an environment, appropriate electronic platforms are created for each learner and teacher. A personalized electronic platform (Network Platform) is a virtual ICT object of adaptive information and communication networks, a case component of logical network infrastructure with a temporary flexible architecture that, by its structure and time of existence, meets personalized user needs, and is based on adaptive technology in terms of its formation and use. One of the promising directions for the further improvement of electronic learning systems is the development of a methodological and logical basis for the design of educational systems based on computer ontologies. 


\section{Ontology-Driven Scientific Education Systems}

Today's education ceases to be interpreted as the achievement of a certain level of knowledge and is seen as a phenomenon of "continuity throughout life". Open access to education has changed the model of communication and has wide support among the state, scientists, society and international organizations.

A rich worldwide collection of open-licensed educational resources, lesson plans, textbooks, games, software and other materials have made education more accessible to those who lack such materials and to those with special learning needs. At the same time, there is a formation and development of information culture, culture of training, creation and exchange of achievements, cooperation in a rapidly changing knowledge society. However, open education is not limited to open educational resources. It is formed from open technologies, from an open exchange of educational practices for mutual enrichment of educators. This promotes collaboration and approaches to learning using adaptive technologies [15].

At the heart of scientific-educational and educational-research activity in any thematic direction, the main thing is the analysis of information resources which narratives can be considered as a set of passive systems of knowledge that only reflect certain facts, processes and operational states but do not have rules of their active use. It is also necessary to take into account the constant updating of digital arrays, including their content in the processes of active use $[6,16,21]$.

Requirements for the processes of permanent processing of large volumes of dispersed and heterogeneous information and educational resources provide for uniformity and clarity of presentation of these resources. Today, the most effective means of such presentation and processing is ontological engineering. It provides an effective transition in the field of information management from data management, which characterizes the quantitative aspect of information processes, to knowledge management, reflecting the qualitative component of these processes. And the need for high-quality processing of these processes necessitates the creation of effective methods and means of obtaining, analyzing and converting such information sources into a convenient form for processing.

The analysis of the studied information sources is complicated by the fact that a significant part of them is contained in poorly structured or unstructured documents [6]. Therefore, it is important to identify the described objects, as well as their characteristics and relationships among them. The problem can be solved through the creation of cognitive IT tools, which are based on determining the patterns of learning objects, as well as the hyper properties of domain objects. This creates the conditions for effective monitoring of different states of resources, and their impact on subjective activities based on ontological modelling, its functioning and the use of methods and means of the rational selection of information processes that make it up. The ontological approach is based on the classification, taxonomization and categorization of all types of educational activities and provides an aggregate reflection of all information states that make up the subject activity in the information space $[6,17]$. 
Cognitive technologies $[6,18]$ are considered as a system of methods, algorithms, programs that model and enhance the cognitive abilities of people to perform practical tasks and which are based on data on the processes of cognition, learning, communication, computer information technology and some other spheres.

The development of cognitive tools digital platforms of scientific education is designed to ensure the aggregate use of electronic educational resources by educational institutions, namely:

- providing wide access to arbitrary format, technology and standards for creating online educational information sources and resources based on semantic management (Semantic Web);

- processing of large volumes of network educational information sources (Big Data);

- selection of data from spatially distributed information sources (Data Mining);

- creation of network electronic platforms of educational institutions and offices of learners, teachers, methodologists, parents;

- formation of personalized trajectories of learners' educational activity.

One of the possible approaches to structuring and formalizing information sources in the public education systems is providing the user with a coherent, systemic review of the certain domain - conceptualization of a field of knowledge, presented by identification of basic objects and links between them. Herewith, the generally accepted, semantically meaningful "conceptual units" of information resources used by learners are determined; results of integration and aggregation of distributed information sources and resources in the process of realization of educational tasks in an easily accessible visual form are visualized. In computer science, ontology is a formal representation of knowledge by a set of concepts within a domain and the relationships between those concepts. It is used to reason about the properties of that domain and may be used to describe it.

In theory, ontology is a formal, explicit specification of a shared conceptualization. Ontology provides a shared vocabulary that can be used to model a domain, type of objects and/or concepts that exist, their properties and relationships [19]. Computer ontology of the subject discipline can be considered as an open knowledge base, which is presented in the common (formal) language of the specification. In the ontological-classification scheme of tools and methods of artificial intelligence, the ontological approach is treated as a kind of systemic, knowledge-based approach. The ontological approach provides effective design components for any knowledge-centred information system.

Computer ontology in this process acts as a valid mechanism for creating digital platforms of scientific education that reflect a certain theory presented as a set of terms, their links, related descriptions and formal axioms, which facilitates the interpretation and sharing of these terms. Computer ontology can be regarded as a certain explicit conceptualization of the logical theory of some calculus with definite rules, which allows classifying the categories of reality as being presented in the language of values and available in the content of the subject discipline. In addition, ontological methods and systems provide 
a conceptual reflection of links of network information processes and systems in different domains through the system components:

a) sets of concepts as structures of semantic units - notions;

b) formal model of the subject content, presented in a language based on the description of the conceptual system;

c) functional model that ensures the unification of terminology, the logic of processing the taxonomic categories and their links, as well as the axiomatization of processes descriptions, causal relationships and ontology procedures.

There are proposed ontologies for the development, in which terms the interface designers form relevant components of its model; interface generation is carried out in several programming languages on different platforms; both local and network interactions are supported; the interface model is divided into components by the groups of specialists engaged in its development (subject matter experts, programmers, designers) and contains all the data required for its development and computer-aided generation based on the model. Thus, the interface model consists of the following components:

a) dialogue concepts system models (describe a system of domain terms that provide input/output, the method of interface usage, as well as intelligent support for user actions);

b) user task models (describe tasks that may be performed using the software system);

c) presentation models (describe the structure and properties of the visual presentation of interface elements);

d) dialogue scenario models (identify numerous possible states of dialogue and actions to be performed);

e) models of educational system interfaces connection with the software.

\section{Cognitive ICT TEDAOS}

The above models are implemented in TEDAOS software package to create an open educational system, cognitive digital platforms of scientific education. TEDAOS (transdisciplinary educational dialogues of application ontological systems) is a technology for the development of educational and research local and network (distributed) systems based on ontologies and context-semantic analysis (from a local ontology-driven system of the educational process to the system of integrated multifaceted analysis of education information resources through an ontological decision-making system and management of the knowledge formation process) to ensure the interaction of all users of network information and educational environments.

Transdisciplinarity of the ontological system is the partial arrangement of varieties of taxonomic and operational properties of ontological (conceptual) domain models [6, 17]. Visual ontology design methods contribute to a faster and more complete understanding of the domain knowledge structure. The implementation of the technology of ontological integration of distributed information resources is carried out by constructing an ontological graph (Fig. 1), 


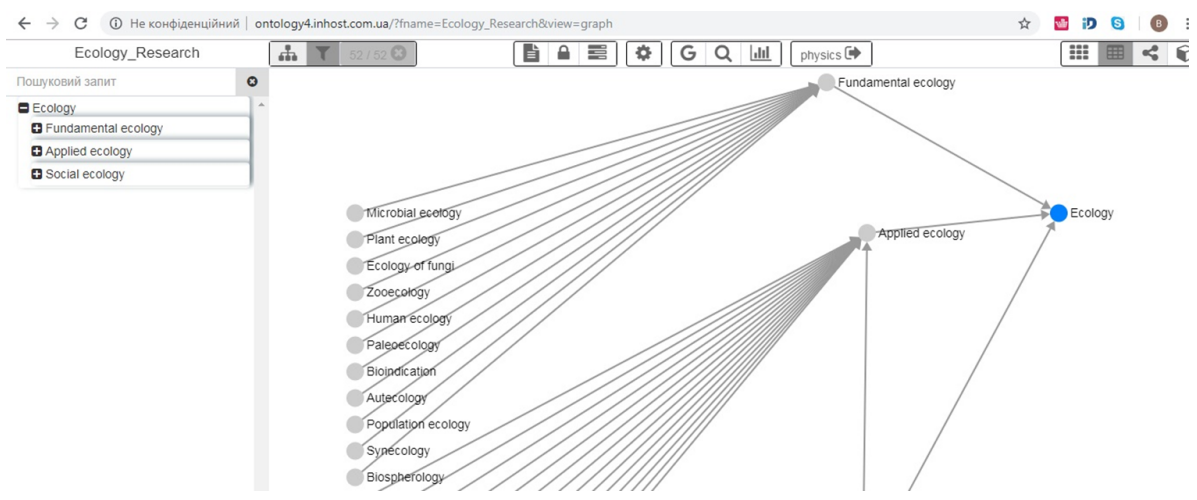

Fig. 1. Example of an ontological graph

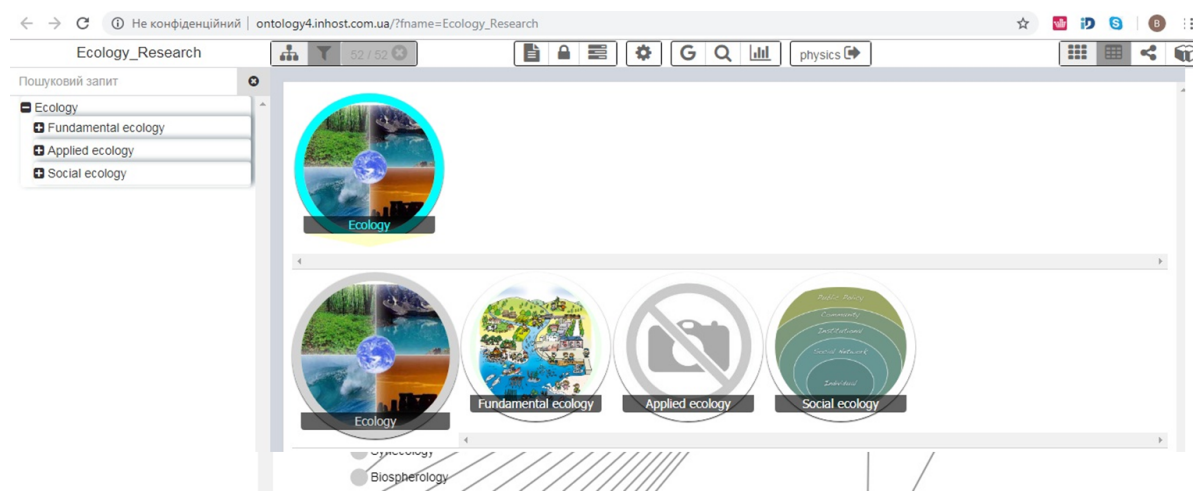

Fig. 2. Example of the object visualization of an ontological graph

the apexes whereof are the concepts and processes of domains (concepts) and their visualization in object mapping (Fig. 2).

TEDAOS software complex is a network and cross-platform. To work with TEDAOS, the user needs to have the basic knowledge of the Windows operating system: the ability to run programmes, work with windows and standard window elements (menus, bookmarks, buttons, drop-down lists, data entry fields, etc.) and operations on the Internet: the ability to navigate to web pages, use standard functions (download files, read, delete, etc.), and also have the simplest operating skills required for the operation with search engines, as well as the ability to work with MS Word text editor and MS Excel spreadsheet. Functionally, the TEDAOS system consists of the following subsystems:

a) CONSPECT (Text Termin) - the construction of terminological trees based on analysis of natural language text;

b) EDITOR (Graph Editor) - the formation of ontological models;

c) SEARCH MACHINE - the search for lexical structures based on linguistic processing of a large number of text arrays;

d) MINDEXER WEB-SERVICE INDEXER — indexing of a site by a special robot (programme) of pages of this site, with subsequent entering data about them into the search engine database. 
The use of ontological models for the formation of an open educational system with the establishment of a domain base allows expanding its functional characteristics and provides the implementation of mechanisms of semantic search of information sources, both in the system itself and on the Internet. Four main components of the ontological interface domain model and, accordingly, four classes of concept systems are identified:

1) user concepts system, in terms of which he/she uses the application. This system of concepts lists the input/output of the application as well as data on the intellectual support for user actions;

2) system of concepts for presenting information sources, in terms of which different types of dialogue are defined. This class contains three types of concept systems: the system of concepts of a graphic user interface; the system of concepts of graphic static scenes; the system of concepts of text formation. Thus, each concept system supports the design of one type of dialogue;

3) system of concepts for defining dialogue scenarios. It defines abstract terms to describe a response to events (sets of actions that occur when events occur, event sources, types of transitions modes between windows, ways of windows instances selection, etc.);

4) system of concepts of links, in terms of which the connection between the application and the interface of the open educational system is carried out. It defines the variables, types of their values that are common to the system interface and application, as well as the protocols for communication, server addresses for connection and the methods of messages transmission.

Information resources of scientific education are presented as natural language structures, reflecting the judgments and statements about certain facts of the subject and thematic profile. Facts are interconnected by sets of links, and may also be characterized by certain properties.

\section{Web-software complex "Knowledge Base Ontological Scenarios Editor" for E-scenario Implementation}

In scientific education, the issue of educational and operational (stepby-step) support of interaction between experts (teachers) of a given domain with participants in the educational process is acute. The issues of creating systems and tools, their practical implementation, providing remote support of education, organization of interaction of all participants in the educational process are becoming relevant. One of such systems is the system of an ontologically structured knowledge base, which provides opportunities to formalize the process of preparation, conduct and evaluation of learning outcomes. An appropriate operating structure is created for this purpose. One of the forms of organization of such a structure is an educational e-scenario.

From the functional point of view, the educational e-scenario is a cognitive, step-by-step, structured system of forming and representation an ontological knowledge base, which is designed to organize the educational interaction of participants in the educational process. The educational e-scenario is 
a personalized ontological system of formalization of the process of information support of the educational process, taking into account the domain, which acts as a means of organizing the knowledge base. The e-scenario is formed operationally, in accordance with the selected object and subject of study and the task. Such scenarios are stored in the knowledge base in the form of ontological graphs and are connected computer-aided or by embedding its information structure in the basic structure of the created e-scenario. Thus, the knowledge base has a component taxonomic structure of the hierarchical type that includes structured e-scenario in narrative discourse format [20].

The knowledge base scenario is a constructed, meaningful image, a component of the knowledge base formed in its environment in the form of contextually related information modules intended for further use as independent sources of knowledge in a given domain. E-scenario can be integrated into the knowledge base belonging to other domains. This creates transdisciplinary scenarios of the knowledge base.

In the theoretical aspect, the information structure of knowledge base scenarios is based on ontology and graph theory. In a formalized form, it is represented by an information structure in which the vertices of the graph and their relationships are displayed and nested folders containing information blocks. The content of information blocks is determined in accordance with the task and the format of the data provided in it.

The general graph structure of the e-scenario of the knowledge base has the following form (Fig. 3).

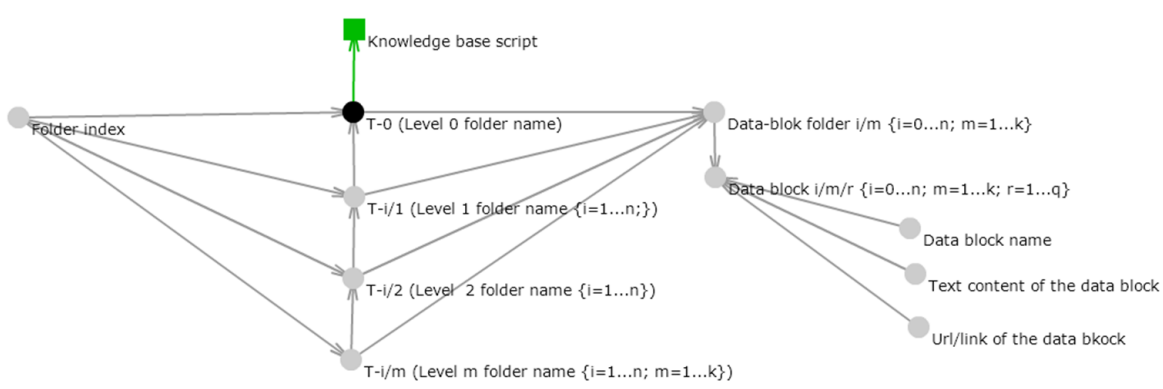

Fig. 3. General educational e-scenario graph structure of the knowledge base

To build an educational e-scenario, a Web-software complex "Knowledge Base Ontological Scenarios Editor" was developed.

The Web-software complex "Knowledge Base Ontological Scenarios Editor" has a wide format of use. These are simple personalized educational scenarios in a given domain and transdisciplinary knowledge bases for both personal and corporate purposes. In this case, the provided e-scenarios can be formalized in the information and application purpose (reference book or textbook) and the management purpose (structure of scientific research) or combine both of these formats at the personal and general (corporate) levels. An interface in the form of a set of screens combined into a prism has been developed to illustrate the presentation of .xml files. Each screen corresponds to a separate element of the ontology and contains links to ontologically structured data blocks. This "prism of knowledge" ("ontoprism") allows you to study 
not only individual concepts (terms), but also to see them in semantic unity with other concepts.

The visualization of the educational e-scenarios $\left({ }^{*} . \mathrm{xml}\right.$ file) is given in Fig. 4.

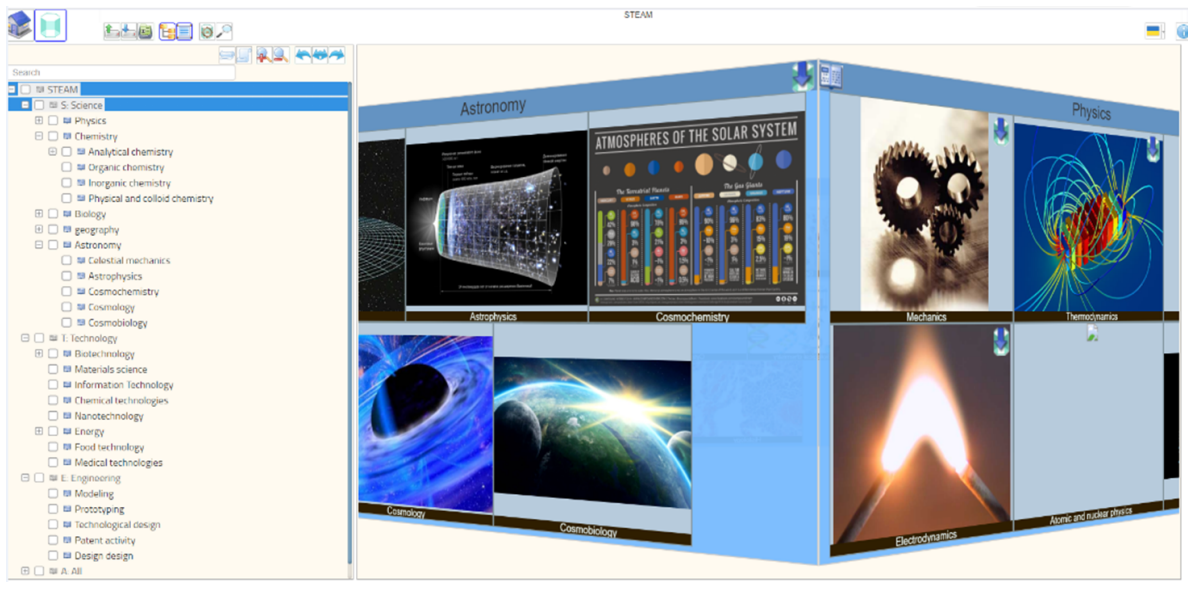

Fig. 4. Educational e-scenario visualization (*.xml file)

\section{Conclusions}

The proposed approach can accomplish scientific education objectives, namely:

a) computer-aided development of knowledge formation bases for educational purposes based on linguistic and semantic analysis of large volumes of text data using original tools, while the source text data may be used from different sources;

b) structuring the terms and concepts of particular subject discipline contained in the information training resources;

c) significant reduction of labour input in compiling knowledge formation bases for educational purposes;

d) multidimensional analysis of learners' educational and cognitive activity;

e) linguistic processing and analysis of linguistic texts using modern contextual semantic analysis tools;

f) experimental and research activities in any field of human activity through knowledge engineering;

g) developing a state-wide distributed distance learning system with the creation of authorized sites for personal and collective interaction;

h) enhancing the knowledge level and formation of a child's scientific outlook by using transdisciplinary approaches in education;

i) increasing the level of training and retraining of educators and scholars.

Thus, the ontological approach in filling the adaptive educational services of digital platforms of scientific education reflects the conceptual system of a certain disciplinary theory and the methodological support of the educational 
and cognitive process consists of mastering the conceptual system, axiomatics, rules, syntactic and morphological foundations of this theory. This provides for the formation of operational space for learners, in which they can interact with other participants of the educational process, based on activity and competence approaches, being in different states of development of this environment. Moreover, the level of conceptual systems acquisition, the disciplines being studied, impact the learner's ability to competently use adaptive educational services, i.e. scientific conceptual theories of subject disciplines, being the knowledge functional core of the domain of a learner educational and cognitive activity. This domain provides integration with environmental components, both at social and thematic-disciplinary levels.

\section{References}

[1] Sakun, A, Mordous, I. 2018. Digital Re-Evolution: Learning to be Human at Contemporary Society. Philosophy and Cosmology 22, 129-136. DOI: $10.29202 /$ philcosm/22/11.

[2] Moser, S., Zumbach, J., Deibl I. 2017. The effect of metacognitive training and prompting on learning success in simulation-based physics learning. Science Education 101(76), 944-967.

[3] Czerkawski, B. Ö. 2015. The semantic web in teacher education. The Turkish Online Journal of Educational Technology 13(4), 144-147.

[4] Algarni, A. 2016. Data Mining in education. International Journal of Advanced Computer Science and Applications. 7(6), 456-61. DOI: 10. 14569/IJACSA.2016.070659.

[5] Mayer-Schönberger V., Cukier K. 2013. Big Data: A Revolution That Will Transform How We Live, Work, and Think. Boston, MA: Houghton Mifflin Harcourt.

[6] Dovgyi S., Stryzhak O. 2020. Transdisciplinary Fundamentals of Information-Analytical Activity. In: Ilchenko M., Uryvsky L., Globa L. (eds) Advances in Information and Communication Technology and Systems. MCT 2019. Lecture Notes in Networks and Systems, vol 152. Springer, Cham. DOI: 10.1007/978-3-030-58359-0_7.

[7] Popova M., Novogrudska R. 2020. Transdisciplinary System for Student Youth Educational and Research Activities Support. IEEE 15th International Conference on Computer Sciences and Information Technologies (CSIT 2020), 320-323. Zbarazh, Ukraine. DOI: 10.1109/CSIT49958.2020. 9321894.

[8] Leach, J. 2008. Do new information and communications technologies have a role to play in the achievement of education for all? British Educational Research Journal 34(6), 783-805.

[9] Artal Sevil, J.S., Romero Pascual, E., Artacho Terrer, J.M. 2016. Simulation-based learning: An interactive tool to increase the student's motivation in higher education. 10th INTED Proceedings, 3621-3630. DOI: 10. 21125/inted.2016.1875.

[10] Pierson, A.E., Clark D.B. 2018. Engaging students in computational modeling: The role of an external audience in shaping conceptual learning, model quality, and classroom discourse. Science Education, 102(6), 13361362. DOI: $10.1002 /$ sce. 21476. 
[11] Brinson, J.R. 2015. Learning outcome achievement in non-traditional (virtual and remote) versus traditional (hands-on) laboratories: A review of the empirical research. Computer Education 87, 218-237.

[12] Schuck, S, Aubusson P. 2010. Educational scenarios for digital futures. Learning. Media and Technology 35(3), 293-305. DOI: 10.1080/17439884. 2010.509351.

[13] Chandrasekaran, A, Linderman, K. 2015. Managing knowledge creation in high-tech R\&D projects: A multimethod study. Decision Sciences 46(2), 267-300.

[14] Yalcin, N., Utku K. 2015. Educational material development model for teaching computer network and system management. Computer Applications in Engineering Education 23(4), 621-629. DOI: 10.1002/cae.21636.

[15] Demianenko, Val., Demianenko, Vik. 2017. Ontological aspects of educational services of adaptive learning. Scientific notes: collection of scientific articles 33, 68-78.

[16] Globa L., Kovalskyi M., Stryzhak O. 2015. Increasing Web Services Discovery Relevancy in the Multi-ontological Environment. In: Wiliński A., Fray I., Pejaś J. (eds) Soft Computing in Computer and Information Science. Advances in Intelligent Systems and Computing, vol 342. Springer, Cham. DOI: 10.1007/978-3-319-15147-2_28.

[17] Stryzhak O., Prychodniuk V., Podlipaiev V. 2019. Model of Transdisciplinary Representation of GEOspatial Information. In: Ilchenko M., Uryvsky L., Globa L. (eds) Advances in Information and Communication Technologies. UKRMICO 2018. Lecture Notes in Electrical Engineering, vol 560. Springer, Cham. DOI: 10.1007/978-3-030-16770-7_3.

[18] Konar A. 2005. Cognitive Engineering: A Distributed Approach to Machine Intelligence. Series: Advanced Information and Knowledge Processing. DOI: 10.1007/1-84628-234-9.

[19] Man, D. 2013. Ontologies in computer science. Didactica mathematica 31(1), 43-46.

[20] Dovhyi, S., Stryzhak, O., Demianenko, V., Kalnoy, S., Lisovyi, O., Prykhodniuk, V., Savchenko, I., Guralyuk, A. 2020. WEB-program complex "Editor of Ontological Scenarios of Knowledge Base": methodical recommendations on creation of electronic educational resources on the basis of use of cognitive services of a complex of formation of ontological scenarios. Kyiv, National Center "Junior Academy of Sciences of Ukraine".

[21] Stryzhak O., Dovgyi S., Popova M., Chepkov R. 2021. Transdisciplinary Principles of Narrative Discourse as a Basis for the Use of Big Data Communicative Properties. In: Arai K. (eds) Advances in Information and Communication. FICC 2021. Advances in Intelligent Systems and Computing, 1364, 258-273. Springer, Cham. DOI: 10.1007/978-3-030-731038 - 17. 